\title{
Banff 2011 Meeting Report: New Concepts in Antibody-Mediated Rejection
}

\author{
M. Mengel ${ }^{a, b},{ }^{*}$, B. Sis ${ }^{a, b}$, M. Haas ${ }^{c}$, R. B. Colvin ${ }^{d}$, P. F. Halloran ${ }^{b}$, L. C. Racusen ${ }^{e}, K$ Solez $^{a}$, \\ L. Cendales ${ }^{f}$, A. J. Demetris ${ }^{g}$, C. B. Drachenberg ${ }^{h}$, C. F. Farveri, E. R. Rodriguez ${ }^{i}$, W. D. \\ Wallace ${ }^{\mathrm{j}}, \mathrm{D}$. Glotz ${ }^{\mathrm{k}}$, and as the Banff meeting report writing committee \\ aDepartment of Laboratory Medicine and Pathology, University of Alberta, Edmonton, Canada \\ bDepartment of Medicine, Alberta Transplant Applied Genomics Centre, Division of Nephrology \& \\ Immunology, University of Alberta, Edmonton, Canada \\ 'Department of Pathology and Laboratory Medicine, Cedars-Sinai Medical Center, Los Angeles, \\ $\mathrm{CA}$ \\ dDepartment of Pathology, Harvard Medical School and Massachusetts General Hospital, Boston, \\ MA \\ eDepartment of Pathology, Johns Hopkins University, Baltimore, MD \\ fEmory Transplant Center, Emory University School of Medicine and Atlanta Veterans Affairs \\ Medical Center, Atlanta, GA \\ gDivision of Transplantation Pathology, Department of Pathology, University of Pittsburgh, \\ Pittsburgh, PA \\ hDepartment of Pathology, University of Maryland, Baltimore, MD \\ 'Department of Anatomic Pathology, Cleveland Clinic, Cleveland, $\mathrm{OH}$ \\ iDepartment of Laboratory Medicine and Pathology, University of California, Los Angeles, CA \\ kDepartment of Nephrology, Hospital Saint-Louis, Paris, France
}

\section{Abstract}

The 11th Banff meeting was held in Paris, France, from June 5 to 10, 2011, with a focus on refining diagnostic criteria for antibody-mediated rejection (ABMR). The major outcome was the acknowledgment of C4d-negative ABMR in kidney transplants. Diagnostic criteria for ABMR have also been revisited in other types of transplants. It was recognized that ABMR is associated with heterogeneous phenotypes even within the same type of transplant. This highlights the necessity of further refining the respective diagnostic criteria, and is of particular significance for the design of randomized clinical trials. A reliable phenotyping will allow for definition of robust end-points. To address this unmet need and to allow for an evidence-based refinement of the Banff classification, Banff Working Groups presented multicenter data regarding the reproducibility of features relevant to the diagnosis of ABMR. However, the consensus was that more data are

(C) Copyright 2012 The American Society of Transplantation and the American Society of Transplant Surgeons

*Corresponding author: Michael Mengel, mmengel@ualberta.ca.

Conflict of interest

Michael Mengel and Banu Sis received a research grant from Astellas Canada in support for the Banff Working Group activities. Michael Mengel is a consultant to Novartis Canada. Denis Glotz received honoraria/speaker's fees from Roche, Novartis, Pfizer, Genzyme, Alexion, ORS, CSL Behring. None of the other authors has any conflicts of interest to disclose as described by the American Journal of Transplantation. 
necessary and further Banff Working Group activities were initiated. A new Banff working group was created to define diagnostic criteria for ABMR in kidneys independent of C4d. Results are expected to be presented at the 12th Banff meeting to be held in 2013 in Brazil. No change to the Banff classification occurred in 2011.

\section{Keywords}

Allograft rejection; allograft transplantation; antibody-mediated rejection; Banff classification

\section{Introduction}

The 11th Banff Conference on Allograft Pathology was held in Paris, France from June 5 to 10, 2011. A total of 288 transplant pathologists, clinicians, surgeons, immunologists and researchers from more than 30 countries discussed aspects relevant to the specific types of organ transplants. Furthermore, Banff Working Groups (BWGs) provided progress reports on activities conducted over the past 2 years. The major focus of discussions was antibodymediated rejection (ABMR) in all types of organ transplants. The most relevant outcome in this regard was the recognition of C4d-negative ABMR in kidney allografts.

\section{New Concepts in Antibody-Mediated Rejection}

\section{Assessing and managing the presensitized patient}

The 11th Banff meeting started with a 1-day premeeting on the diagnostic and therapeutic challenges in presensitized patients. The presence of donor-specific antibodies (DSA) at or before transplantation is associated with an increased frequency of ABMR and inferior outcome. But not all antibodies detected by highly sensitive assays cause a phenotype in the allograft and not all antibody-mediated phenotypes inevitably cause accelerated allograft failure. Thus the need for reliable risk stratification was identified. Various approaches to address this unmet need were discussed: measuring mean fluorescence intensity levels of DSA $(1,2)$, the calculated PRA to better assess the risk pretransplant (3), subtyping of IgGanti-HLA antibodies (4) and identification of C1q-fixing donor-specific antibodies (5). However, there is yet no consensus on relevant thresholds for the various method platforms which are associated with various degrees of sensitivity and specificity. Numerous factors (e.g. treatment with therapeutic antibodies, data normalization) can interfere with the result from antibody testing, in particular for flow-based cross-matches $(6,7)$. To mitigate the ongoing deficit in this area, collaborative standardization efforts are underway (8). However, at this stage the transplant community has to accept that all antibody assays have limitations, which need to be taken into account when test results are interpreted.

In kidney transplantation a large variety of desensitization protocols have been described, with IVIG used most frequently (9). Overall successful desensitization is associated with improved patient survival compared to long-term dialysis (10).

Most therapeutic tools for sensitized patients were transferred from other areas into transplantation. These include plasma exchange and drugs such as IVIG, rituximab, bortezomib and eculizumab. There is evidence that applying one of these modalities alone is less effective than the combination of several (11). Thus the need is for well-designed randomized clinical trials, in which combination therapies would be tested (12). It was emphasized at this meeting and at a recent FDA workshop (13) that the ability to correctly define antibody-mediated phenotypes in allografts is essential for adequately powering randomized clinical trials. Defining the ABMR phenotype including activity grading and chronicity staging is challenging and requires that the various aspects of $\mathrm{ABMR}$ are taken 
into account: the nature of the antibody, the significance of C4d, allograft pathology, allograft function and outcome. Two major phenotypes of ABMR were identified: phenotype 1-ABMR developing in the presensitized patient early posttransplantation and phenotype 2-ABMR after de novo DSA developing late posttransplantation, mostly in relation to noncompliance (14). Phenotype 2 represents a significant contributor to late renal allograft loss (14-17). Against this background the aim of a randomized clinical trial needs to be clearly defined. If it is the prevention of phenotype 1 ABMR in the presensitized patient, the diagnosis of ABMR would be the end-point. A trial involving phenotype 2 patients, the diagnosis of ABMR would be the entry point into the trial and the amelioration of the ABMR phenotype would be the end point. It was pointed out that in addition to antibody measurement, $\mathrm{C} 4 \mathrm{~d}$ staining and histopathology, molecular measurements $(18,19)$ can help to grade and stage disease activity and progression.

\section{Diagnosis, grading and staging of antibody-mediated injury in kidney allografts}

The challenges in diagnosis, grading and staging of ABMR include the facts that morphological features are dependent on the time point in the course of the disease, and the dynamics of the disease course show significant individual variability. In this context it is important to note that the term "chronic" is not related to a certain time posttransplantation but indicates morphological changes of remodeling seen in the allograft due to antibodymediated injury, e.g. double contours of glomerular basement membranes (GBM). The groups from Paris showed that in presensitized patients persistent subclinical microcirculation inflammation (MI = capillaritis and/or glomerulitis) leads to chronic microvascular remodeling (= transplant glomerulopathy and peritubular capillary basement membrane multilayering) $(20,21)$. These cases were frequently C4d negative despite the presence of DSA and MI. The risk of progressing to chronic ABMR was also independent of $\mathrm{C} 4 \mathrm{~d}$ and primarily driven by the presence of DSA and MI. Furthermore, the same groups presented compelling data indicating that the progression of allograft arteriosclerosis in large arteries is associated with DSA and the diagnosis of ABMR, independently of other classical risk factors (aging, hypertension, diabetes) $(22,23)$. Recent data show that Banff v1 and v2 lesions, i.e. intimal arteritis that is traditionally attributed to TCMR, have an association with ABMR (24). Preliminary data were presented by Anthony Chang and coworkers (University of Chicago) at the meeting indicating that immunophenotyping of intimal arteritis reveals significantly higher numbers of NK cells (CD56+) in the subendothelial infiltrate of vlesions in the setting of ABMR compared to TCMR.

The significance of MI in sensitized patients under the influence of treatment was discussed in detail. Early biopsies from presensitized patients treated with eculizumab were diffusely C4d positive but did not show morphological signs of ABMR including lack of endothelial cell activation by electron microscopy (25). Early assessment by electron microscopy (e.g. $<3$ months post-Tx) in sensitized patients turned out to be very sensitive for the detection of endothelial injury (26), but the observed changes were not predictive of later development of TG in eculizumab-treated patients. The fact that complement component $\mathrm{C} 5$ as the target of eculizumab is downstream of $\mathrm{C} 4 \mathrm{~d}$ explains the diffuse positivity for $\mathrm{C} 4 \mathrm{~d}$, while the lack of respective pathology suggests that eculizumab simultaneously protects the endothelium. However, some patients developed chronic ABMR with TG despite eculizumab. This highlights that complement inhibition alone does not prevent the development of chronic, antibody-mediated MI, and also illustrates limitations in the diagnostic reliability of C4d and DSA. This leaves morphology as crucial for diagnosis, staging and grading of ABMR with MI emerging as the most significant harbinger of later signs of chronic $\operatorname{ABMR}(27,28)$.

But the specificity of ABMR-associated histological lesions is limited as well. Glomerulitis can occur in TCMR and responds to steroid treatment (29). And there is still an ongoing debate about the exact percentage of cases with GBM double contours not attributable to 
DSA. The numbers vary between $20 \%$ and $50 \%$ with some cases being attributable to thrombotic microangiopathy and/or hepatitis $\mathrm{C}$ (30). Thus the most important challenge currently faced by the Banff community lies in identifying clinically relevant thresholds and reproducible criteria for assessing antibody-mediated microcirculation injury in renal allografts.

\section{Banff Working Group (BWG) activities}

Banff Working Groups were established at the 2009 meeting with the aim of conducting multicenter trials to evaluate the clinical relevance, practical feasibility and reproducibility of potential evidence-based changes to the Banff classification (31). Preliminary results and current activity status of the BWGs are summarized in Table 1. Detailed reports from all BWG activities will be published separately.

\section{Banff working lunch and online discussions on C4-negative ABMR}

Significant limitations of $\mathrm{C} 4 \mathrm{~d}$ as a diagnostic marker for ABMR were identified. According to the current Banff classification only diffuse $\mathrm{C} 4 \mathrm{~d}$ staining by immunofluorescence on frozen sections or at least focal staining by immunoperoxidase on paraffin sections can be called ABMR (31). C4d-negative cases showing MI in the presence of DSA are termed suspicious for ABMR. It is evident that $\mathrm{C} 4 \mathrm{~d}$ is of limited sensitivity due to methodologic issues, but also due to real biological phenomena like noncomplement fixing antibodies, waxing and waning of $\mathrm{C} 4 \mathrm{~d}$ deposition or reduced capillary density. In addition, positive staining for $\mathrm{C} 4 \mathrm{~d}$ without MI or graft dysfunction can be observed in AB0-incompatible cases and patients treated with eculizumab. The existence of C4d-negative ABMR as a phenotype has been broadly accepted by the participants of a working lunch at the 11th Banff meeting. A new working group was established with the goal of defining and validating reproducible, relevant and clinically feasible diagnostic criteria for C4d-negative ABMR. In this regard, the detection of NK cells and endothelial activation may be helpful in identifying C4d-negative cases $(18,19)$. It was acknowledged that it is crucial to prevent over-diagnosing ABMR since treatment is significant in terms of side effects and costs. To this end there remain important issues that need to be resolved before a diagnostic category of C4d-negative ABMR can be added to the Banff classification. These include:

1. Defining appropriate thresholds for microvascular injury and for DSA that provide an optimal balance of specificity and sensitivity for ABMR, noting that none of these morphologic changes are specific and that not all patients with DSA have ABMR.

2. Defining "C4d-negative". There is some evidence that focal $\mathrm{C} 4 \mathrm{~d}$ is often (though less so than diffuse C4d) associated with DSA and microvascular injury (32).

3. Defining acute versus chronic/active ABMR.

4. Defining the significance of intimal arteritis (in the absence of necrosis) as histologic evidence for ABMR.

\section{Novel insights from kidney allograft protocol biopsies}

New findings emerged from studies of both early and late protocol biopsies of renal allografts.

1. MI ( \pm C4d positivity) may be seen in early protocol biopsies, although this is most often observed in patients with some immunologic risk for sensitization.

Nonetheless, this early subclinical injury does correlate with an increased risk for later development of TG in nonsensitized patients, just as it does in patients with pre-existing DSA. 
2. The use of immunosuppressive regimens utilizing tacrolimus in lieu of cyclosporine with mycophenolate mofetil results in reduced levels of IFTA, interstitial inflammation in both scarred and nonscarred areas, and evidence of chronic microvascular injury during the first $4-5$ years posttransplantation (33). However, the significance of some of these differences was lost at later time points, and there was no improvement in death-censored graft or patient survival. This may reflect chronic calcineurin inhibitor $(\mathrm{CNI})$ nephrotoxicity. This assumption fueled a lively debate about the significance of CNI nephrotoxicity as a contributor to renal allograft deterioration, particularly against the background of recent data indicating that no specific morphological lesions for CNI nephrotoxicity exist (34). However, this issue will require more long-term data from trials using noninferior CNI-free immunosuppression protocols.

3. Molecular analysis of early ( 6 week) protocol biopsies provides evidence that mild subclinical TCMR has a molecular signature similar to that of injury-induced inflammation and is different from clinical overt TCMR in time-matched indication biopsies (35). Furthermore, early subclinical infiltrates were not associated with subsequent progression of IFTA, even when untreated. These findings suggest that very early protocol biopsies reflect prior injury and are of limited value in nonsensitized recipients for predicting the future course. In contrast, molecular studies of 1-year protocol biopsies showed expression of many profibrotic genes in both histologically normal biopsies and those showing IFTA without inflammation. However, a subset of 1-year protocol biopsies with IFTA+inflammation showed a different expression profile and was associated with progressive deterioration (36). This indicated that in later protocol biopsies a subgroup of patients with subclinically progressive injury exists which needs to be better understood.

4. Studies of urine and blood biomarkers have potential to identify recipients with subclinical TCMR, thus reducing the need for protocol biopsies. Analysis of urine metabolites identified differences in patients with and without subclinical TCMR, and normalization of the rejection spectral pattern associated with morphologic resolution of TCMR after treatment. Furthermore, renal graft recipients with operational tolerance have increased circulating numbers of specific memory B-cell populations (37). Notably, a subset of these patients did develop late graft dysfunction, sometimes with TG that may lead to graft loss; loss of these memory B cells from the blood may correlate with these negative outcomes.

In summary, an unselective, general application of protocol biopsies particularly early posttransplant, appears not justified. However, protocol biopsies provide the biggest return of investment in high-risk patients and in cases with a high prior probability for progressive lesions, e.g. early in presensitized patients.

\section{New developments in other organ transplants}

Liver allografts-The liver sessions included three interrelated topics: (1) biopsy findings in long-term immunosuppression management with a focus on defining histopathologic criteria for spontaneous operational tolerance (SOT); (2) role of ABMR and utility of C4d staining; (3) use of emerging technologies to augment histopathology. The first topic is the focus of a consensus document discussed at the 2009 and 2011 meeting. General consensus is that (a) an individualized approach to immunosuppression is needed; (b) biopsy findings are of importance in patient and allograft monitoring and (c) pathologists need to have input in defining SOT. Several groups re-enforced the contribution of antibodies to liver allograft damage, including an inability to wean immunosuppression from recipients showing DSA and diffuse $\mathrm{C} 4 \mathrm{~d}+$ staining. Newer technologies, such as mRNA arrays and multiplex tissue staining/digital slide imaging, were introduced as means to optimize biopsy analysis with the 
following goals: (a) better understand and classify immunologic mechanisms of tissue injury and allograft acceptance; and (b) predict which patients might be successfully weaned from immunosuppression. Upcoming goals of the Banff liver group for 2013 include a better understanding of (1) spectrum of ABMR with consensus guidelines for interpreting $\mathrm{C} 4 \mathrm{~d}$ stains; (2) SOT; (3) donor organ biopsy evaluation and (4) continued integration of newer technologies.

Pancreas allografts-The pancreas group recently published consensus guidelines for the diagnosis of ABMR (38) emphasizing the need for clinicopathological integration for the diagnosis of ABMR in pancreas allografts similar to renal allografts, i.e. DSA, MI and C4d in interacinar capillaries. The pancreas session at the 2011 Banff meeting focused on practical and reproducibility issues for the interpretation of $\mathrm{C} 4 \mathrm{~d}$ staining, the differential diagnostic features of TCMR and ABMR, and histological and clinical features of recurrent autoimmune diabetes mellitus type 1 . Also the systematic use of surveillance and for cause pancreas allograft biopsies and practical difficulties for biopsy graft accessibility were reviewed. Experiences with retroperitoneal enteric-drained pancreas transplants were discussed against enteroscopic biopsies of the duodenal allografts as surrogate samples to detect pancreatic allograft rejection. The group identified four priorities for future studies (1) to determine the impact of protocol biopsies in clinical practice, (2) assess the equality of duodenal cuff versus pancreas parenchyma biopsies, (3) to determine the incidence of islet pathology, (4) to assess and improve if necessary, the reproducibility of the updated Banff grading schema.

Lung allografts-This session focused on reviewing available immunology, serology and pathology data of ABMR in lung allografts and their clinical correlates. Significant gaps in the understanding of ABMR-related pathologic changes in lungs were identified. The group agreed to initiate a study under the auspices of Banff in an attempt to correlate experiences from multiple large lung transplant centers. The study will compile cases of patients who had biopsies and de novo DSA with the aim to identify the most pertinent and reproducible histological lesions that are clinically most relevant. Goal is to develop internationally acceptable recommendations for the pathologic diagnosis of ABMR in lung allografts. In addition to ABMR the relevance of non-BOS chronic graft dysfunction, infectious complications and the role of endothelial cells in vascular pathology and subsequent graft deterioration were reviewed as significant clinical challenges in lung allograft patients.

Vascularized composite allografts (VCA)-The VCA session focused on an update of chronic changes and antibody-mediated findings. Experiences in human and non-humanprimate models suggested ischemic changes, alloimmune injury to skin, transplant arteriopathy and superficial versus deep tissue rejection as the most relevant differential diagnosis occurring in VCA. Vascular intimal thickening, nail changes, loss of hair follicles in the context of the development of DSA and potential consecutive graft loss due to ABMR were discussed. Ultrasound bio-microscopy was identified as a monitoring tool for graft vascular changes. Vascular narrowing appears to be related with myointimal proliferation, loss of adnexa, skin atrophy, fibrosis of deep tissue, endarteritis and endothelialitis as potential long-term alloimmune-mediated changes in VCA. Thus the following priorities for future research in the VCA area were identified: validation of the current Banff VCA classification (39), interpretation of long-term changes and related biomarkers, differential diagnosis of inflammation versus rejection, ABMR, significance of myointimal proliferation.

Heart allografts-A major focus of the 2011 Banff meeting was the further refinement of the recently revised diagnostic criteria for ABMR in heart allografts (40). In this regard 
numerous research studies were reviewed and collaborative future efforts were discussed. A detailed report summarizing the outcome from these discussions will be published separately.

\section{The role of epithelium in allograft deterioration}

Data regarding epithelial injury and repair processes in different types of organ transplants were reviewed. With this it became obvious that no robust evidence is available that a phenomenon called "Epithelial Mesenchymal Transition" (EMT) truly exists in organ transplants. There was broad acceptance of the fact that epithelial cells in situ can change their phenotype toward a mesenchymal one. However, no evidence was available that such a dedifferentiated epithelial cell actually migrates across its basement membrane into the adjacent interstitium and starts to lay down collagen. Elegant molecular, mechanistic and imaging data were provided demonstrating that all epithelial cells in a variety of organs (tubular by Groene and Hertig; biliary by Kirby et al.; bronchial by Fisher et al.) show a highly stereotyped response to any kind of injury. This includes the re-expression of embryonic and developmental pathways and with this epithelial cells assume a more mesenchymal phenotype as a sign of dedifferentiation, which often represents a transient state (41). The expression of the mesenchymal phenotype frequently colocalizes with increased inflammation and matrix production in the adjacent interstitium. However there is no convincing evidence that the source of fibrosis is the migrated, dedifferentiated epithelial cell, but rather an adjacent, residential interstitial cell.

During an online discussion after the Banff meeting, consensus was reached that continuing to use the term EMT would be misleading since no reliable evidence for a transition/ migration of epithelial cells across the basement membrane is available in organ transplants. Various terms were discussed with the aim to encompass the phenomenon of epithelial dedifferentiation during the response-to-injury and the following repair processes. However, it also became obvious that the two processes, i.e. dedifferentiation and injury-repair, are not inevitably interconnected and still ill-defined. Therefore, the development of a new consensus term was postponed to future Banff meetings, with expectation of further studies of this important phenomenon.

\section{Acknowledgments}

The participants of the 11th Banff Conference gratefully acknowledge the financial support provided by the following companies and institutions: Astellas, Novartis, Roche, Pfizer, One Lambda, CSL Behring, Transpath, Alexion, Aperio, Philips, Omnyx, University of Alberta, National Kidney Foundation and Renal Pathology Society.

\section{Abbreviations}

$\begin{array}{ll}\text { ABMR } & \text { antibody-mediated rejection } \\ \text { BWG } & \text { Banff Working Group } \\ \text { CXM+ } & \text { positive cross-match } \\ \text { CNI } & \text { calcineurin inhibitor } \\ \text { DSA } & \text { donor-specific antibody } \\ \text { FDA } & \text { Food and Drug Administration } \\ \text { IFTA } & \text { interstitial fibrosis and tubular atrophy } \\ \text { MI } & \text { microcirculation inflammation, i.e. glomerulitis and/or capillaritis } \\ \text { TCMR } & \text { T-cell-mediated rejection }\end{array}$


TG transplant glomerulopathy

V-Score Banff intimal arteritis score

VCA vascularized composite allograft

\section{References}

1. Gloor JM, Degoey S, Ploeger N, et al. Persistence of low levels of alloantibody after desensitization in crossmatch-positive living-donor kidney transplantation. Transplant. 2004; 78:221-227.

2. Lefaucheur C, Loupy A, Hill GS, et al. Preexisting donor-specific HLA antibodies predict outcome in kidney transplantation. J Am Soc Nephrol. 2010; 21:1398-1406. [PubMed: 20634297]

3. Lefaucheur C, Antoine C, Suberbielle C, Glotz D. Mastering the risk of HLA antibodies in kidney transplantation: An algorithm based on pretransplant single-antigen flow bead techniques. Am J Transplant. 2011; 11:1592-1598. [PubMed: 21668626]

4. Ravindranath MH, Kaneku H, El-Awar N, Morales-Buenrostro LE, Terasaki PI. Antibodies to HLA-E in nonalloimmunized males: Pattern of HLA-Ia reactivity of anti-HLA-E-positive sera. J Immunol. 2010; 185:1935-1948. [PubMed: 20610644]

5. Shapiro R, Lunz J, Zeevi A, et al. 1.7 year follow-up after bortezomib therapy for refractory antibody mediated rejection. Clin Transpl. 2010:405-407. [PubMed: 21696058]

6. Zachary AA, Montgomery RA, Locke JE, Leffell MS. Proinflammatory events and HLA antibodies. Am J Transplant. 2010; 10:956. [PubMed: 20148814]

7. Gloor JM, Moore SB, Schneider BA, DeGoey SR, Stegall MD. The effect of antithymocyte globulin on anti-human leukocyte antigen antibody detection assays. Transplant. 2007; 84:258-264.

8. Gebel HM, Bray RA. The evolution and clinical impact of human leukocyte antigen technology. Curr Opin Nephrol Hypertens. 2010; 19:598-602. [PubMed: 20720491]

9. Jordan SC, Vo AA, Peng A, Toyoda M, Tyan D. Intravenous gammaglobulin (IVIG): A novel approach to improve transplant rates and outcomes in highly HLA-sensitized patients. Am J Transplant. 2006; 6:459-466. [PubMed: 16468954]

10. Montgomery RA, Lonze BE, King KE, et al. Desensitization in HLA-incompatible kidney recipients and survival. N Engl J Med. 2011; 365:318-326. [PubMed: 21793744]

11. Lefaucheur C, Nochy D, Andrade J, et al. Comparison of combination plasmapheresis/IVIg/antiCD20 versus high-dose IVIg in the treatment of antibody-mediated rejection. Am J Transplant. 2009; 9:1099-1107. [PubMed: 19422335]

12. Gloor J, Stegall MD. Sensitized renal transplant recipients: Current protocols and future directions. Nat Rev Nephrol. 2010; 6:297-306. [PubMed: 20234355]

13. Archdeacon P, Chan M, Neuland C, et al. Summary of FDA antibody-mediated rejection workshop. Am J Transplant. 2011; 11:896-906. [PubMed: 21521465]

14. Halloran PF, de Freitas DG, Einecke G, et al. An integrated view of molecular changes, histopathology, and outcomes in kidney transplants. Am J Transplant. 2010; 10:2223-2230. [PubMed: 20931696]

15. Einecke G, Halloran PF. Antibody-mediated microcirculation injury is the major cause of late kidney transplant failure: Response to Dr. Loupy et al. Am J Transplant. 2009; 9:2520-2531. [PubMed: 19843030]

16. El Zoghby ZM, Stegall MD, Lager DJ, et al. Identifying specific causes of kidney allograft loss. Am J Transplant. 2009; 9:527-535. [PubMed: 19191769]

17. Gaston RS, Cecka JM, Kasiske BL, et al. Evidence for antibody-mediated injury as a major determinant of late kidney allograft failure 1. Transplant. 2010; 90:68-74.

18. Hidalgo LG, Sis B, Sellares J, et al. NK cell transcripts and NK cells in kidney biopsies from patients with donor-specific antibodies: Evidence for NK cell involvement in antibody-mediated rejection. Am J Transplant. 2010; 10:1812-1822. [PubMed: 20659089] 
19. Sis B, Jhangri G, Bunnag S, Allanach K, Kaplan B, Halloran PF. Endothelial gene expression in kidney transplants with alloantibody indicates antibody-mediated damage despite lack of $\mathrm{C} 4 \mathrm{~d}$ staining. Am J Transplant. 2009; 9:2312-2323. [PubMed: 19681822]

20. Loupy A, Suberbielle-Boissel C, Hill GS, et al. Outcome of subclinical antibody-mediated rejection in kidney transplant recipients with preformed donor-specific antibodies. Am J Transplant. 2009; 9:2561-2570. [PubMed: 19775320]

21. Loupy A, Hill GS, Suberbielle C, et al. Significance of C4d Banff scores in early protocol biopsies of kidney transplant recipients with preformed donor-specific antibodies (DSA). Am J Transplant. 2011; 11:56-65. [PubMed: 21199348]

22. Loupy A, Cazes A, Guillemain R, et al. Very late heart transplant rejection is associated with microvascular injury, complement deposition and progression to cardiac allograft vasculopathy. Am J Transplant. 2011; 11:1478-1487. [PubMed: 21668629]

23. Hill GS, Nochy D, Bruneval P, et al. Donor-specific antibodies accelerate arteriosclerosis after kidney transplantation. J Am Soc Nephrol. 2011; 22:975-983. [PubMed: 21493773]

24. Sis B, Einecke G, Chang J, et al. Cluster analysis of lesions in kidney transplant biopsies: Microcirculation changes, tubulointerstitial inflammation, and scarring. Am J Transplant. 2010; 10:421-430. [PubMed: 20055794]

25. Stegall MD, Diwan T, Raghavaiah S, et al. Terminal complement inhibition decreases antibodymediated rejection in sensitized renal transplant recipients. Am J Transplant. 2011; 2011:24052413. [PubMed: 21942930]

26. Wavamunno MD, O'Connell PJ, Vitalone M, et al. Transplant glomerulopathy: Ultrastructural abnormalities occur early in longitudinal analysis of protocol biopsies. Am J Transplant. 2007; 7:2757-2768. [PubMed: 17924997]

27. Cosio FG, Lager DJ, Lorenz EC, Amer H, Gloor JM, Stegall MD. Significance and implications of capillaritis during acute rejection of kidney allografts. Transplant. 2010; 89:1088-1094.

28. Cosio FG, Gloor JM, Sethi S, Stegall MD. Transplant glomerulopathy [Review] [25 refs]. Am J Transplant. 2008; 8:492-496. [PubMed: 18294145]

29. Batal I, Lunz JG III, Aggarwal N, et al. A critical appraisal of methods to grade transplant glomerulitis in renal allograft biopsies. Am J Transplant. 2010; 10:2442-2452. [PubMed: 20977635]

30. Baid-Agrawal S, Farris AB III, Pascual M, et al. Overlapping pathways to transplant glomerulopathy: Chronic humoral rejection, hepatitis $\mathrm{C}$ infection, and thrombotic microangiopathy. Kidney Int. 2011; 80:879-885. [PubMed: 21697808]

31. Sis B, Mengel M, Haas M, et al. Banff '09 Meeting Report: Antibody mediated graft deterioration and implementation of Banff Working Groups. Am J Transplant. 2010; 10:464-471. [PubMed: 20121738]

32. Kedainis RL, Koch MJ, Brennan DC, Liapis H. Focal C4d+ in renal allografts is associated with the presence of donor-specific antibodies and decreased allograft survival. Am J Transplant. 2009; 9:812-819. [PubMed: 19344468]

33. Stegall MD, Park WD, Larson TS, et al. The histology of solitary renal allografts at 1 and 5 years after transplantation. Am J Transplant. 2011; 11:698-707. [PubMed: 21062418]

34. Snanoudj R, Elie C, Rabant M, et al. Specificity of histological markers of long-term CNI nephrotoxicity in kidney transplant recipients under low-dose cyclosporine therapy. Am J Transplant. 2011; 11:2635-2646. [PubMed: 21883915]

35. Mengel M, Chang J, Kayser D, et al. The molecular phenotype of six-week protocol biopsies from human renal allografts: Reflections of prior injury but not future course. Am J Transplant. 2011; 11:708-718. [PubMed: 21114657]

36. Park WD, Griffin MD, Cornell LD, Cosio FG, Stegall MD. Fibrosis with inflammation at one year predicts transplant functional decline. J Am Soc Nephrol. 2010; 21:1987-1997. [PubMed: 20813870]

37. Le TL, Thebault $P$, Lavault A, et al. Long-term allograft tolerance is characterized by the accumulation of B cells exhibiting an inhibited profile. Am J Transplant. 2011; 11:429-438. [PubMed: 21114655] 
38. Drachenberg CB, Torrealba JR, Nankivell BJ, et al. Guidelines for the diagnosis of antibodymediated rejection in pancreas allografts-updated Banff grading schema. Am J Transplant. 2011; 11:1792-1802. [PubMed: 21812920]

39. Cendales LC, Kanitakis J, Schneeberger S, et al. The Banff 2007 working classification of skincontaining composite tissue allograft pathology. Am J Transplant. 2008; 8:1396-1400. [PubMed: 18444912]

40. Berry GJ, Angelini A, Burke MM, et al. The ISHLT working formulation for pathologic diagnosis of antibody-mediated rejection in heart transplantation: Evolution and current status (2005-2011). J Heart Lung Transplant. 2011; 30:601-611. [PubMed: 21555100]

41. Einecke G, Kayser D, Vanslambrouck JM, et al. Loss of solute carriers in T cell-mediated rejection in mouse and human kidneys: An active epithelial injury-repair response. Am J Transplant. 2010; 10:2241-2251. [PubMed: 20883558]

\section{Appendix}

\section{Faculty at the 2011 Banff meeting}

Akalin, Enver (UK), Alexander, Graeme (USA), Anglicheau, Dany (France), Askar, Medhat, (USA), Belperio, John (USA), Boehmig, Georg (Austria), Boggi, Ugo (Italy), Bracamonte, Rika (USA), Bröcker, Verena (Germany), Rouard, Sophie (France), Cecka, Michael (USA), Cendales, Linda (USA), Chang, Anthony (USA), Chelmonski, Adam (Poland), Colvin, Obert B. (USA), Cornell, Lynn (USA), Demetris, Anthony Jake (USA), Drachenberg, Cinthia B. (USA), Duong van Huyen, Jean Paul (France), Einecke, Gunilla (Germany), Farver, Carol (USA), Farris, Alton B. (USA), Fedrigo, Marny (Italy), Feng, Sandy (USA), Fisher, Andrew (UK), Gebel, Howard (USA), Gloor, James (USA), Glotz, Denis (France), Gröne, Hermann-Josef (Germany), Haas, Mark (USA), Hachem, Ramsey (USA), Haga, Hironori (Japan), Halloran, Philip (Canada), Hautz, Theresa (Austria), Hertig, Alexandre (France), Hidalgo, Luis (Canada), Hill, Gary (France), Hübscher, Stefan (UK), Isse, Kumiko (USA), Iversen, Martin (Denmark), Johnson, Maryl (USA), Jordan, Stanley C. (USA), Kanitakis, Jean (France), Kaufman, Christina (USA), Kim, Dae Un (USA), Kirby, John Andrew (UK), Koshiba, Takaaki (Japan), Kraus, Edward (USA), Lefaucheur, Carmen (France), Leuvenink, Henri (The Netherlands), Liapis, Helen (USA), Loupy, Alexandre (France), Mannon, Roslyn B. (USA), Margreiter, Christian (Austria), Marisa Crespo-Leiro (Spain), Mengel, Michael (Canada), Montgomery, Bob (USA), Mundinger, Gerhard (USA), Musat, Alexandru (USA), Nankivell, Brian (Australia), Nickeleit, Volker (USA), Pallet, Nicolas (France), Papadimitriou, John (USA), Park, Walter (USA), Racusen, Lorraine (USA), Randhawa, Parmjeet (USA), Rangel, Erika (Brazil), Reeve, Jeff (Canada), Rodriguez, Rene (USA), Rose, Marlene (UK), Roysam, Badrinath (USA), Ruiz, Phillip (USA), Rush, David (Canada), Sánchez-Fueyo, Alberto (Spain), Sebagh, Mylene (France), Séron, Daniel (Spain), Sis, Banu (Canada), Solez, Kim (Canada), Stegall, Mark (USA), Tan, Carmela D. (USA), Terasaki, Paul (USA), Thervet, Eric (France), van Huyen, Jean Paul Duong (France), Wallace, William (USA), Woodle, Steven (USA), Zachary, Andrea (USA), Zeevi, Adriana (USA). 
Table 1

Scope, preliminary results and activity status of current Banff Working Groups

\begin{tabular}{|c|c|c|c|c|}
\hline $\begin{array}{l}\text { Banff Working Group } \\
\text { (BWG) }\end{array}$ & Scope & Preliminary results & Current activity status & $\begin{array}{l}\text { Lead and } \\
\text { contact person }\end{array}$ \\
\hline $\begin{array}{l}\mathrm{C} 4 \mathrm{~d}-\text { Banff initiative for } \\
\text { quality assurance in } \\
\text { transplantation (BIFQUIT) }\end{array}$ & $\begin{array}{l}\text { Assessment of } \\
\text { interlaboratory and } \\
\text { interobserver } \\
\text { reproducibility of C4d } \\
\text { immunohistochemistry in } \\
\text { paraffin-embedded kidney } \\
\text { allograft specimens }\end{array}$ & $\begin{array}{l}\text { A fair to moderate } \\
\text { reproducibility between } \\
\text { laboratories and observers } \\
\text { was observed. Also data } \\
\text { regarding the optimal } \\
\text { staining protocol were } \\
\text { collected }\end{array}$ & $\begin{array}{l}\text { Trial and data analysis } \\
\text { completed. Manuscript in } \\
\text { preparation }\end{array}$ & $\begin{array}{l}\text { Michael Mengel, } \\
\text { University of } \\
\text { Alberta, } \\
\text { Edmonton, } \\
\text { Canada } \\
\text { Parmjeet } \\
\text { Randhawa, } \\
\text { University of } \\
\text { Pittsburgh, } \\
\text { Pittsburgh, USA }\end{array}$ \\
\hline $\begin{array}{l}\text { BK - Banff initiative for } \\
\text { quality assurance in } \\
\text { transplantation (BIFQUIT) }\end{array}$ & $\begin{array}{l}\text { Assessment of } \\
\text { interlaboratory and } \\
\text { interobserver } \\
\text { reproducibility of } \\
\text { polyomavirus } \\
\text { immunohistochemistry in } \\
\text { paraffin-embedded kidney } \\
\text { specimens }\end{array}$ & $\begin{array}{l}\text { This multicenter trial } \\
\text { revealed that the proposed } \\
\text { scoring system for BK stains } \\
\text { shows a substantial } \\
\text { interobserver reproducibility, } \\
\text { while the interlaboratory } \\
\text { reproducibility is quite } \\
\text { limited. Also data regarding } \\
\text { the optimal staining protocol } \\
\text { were collected }\end{array}$ & $\begin{array}{l}\text { Trial and data analysis } \\
\text { completed. Manuscript in } \\
\text { preparation }\end{array}$ & $\begin{array}{l}\text { Parmjeet } \\
\text { Randhawa, } \\
\text { University of } \\
\text { Pittsburgh, } \\
\text { Pittsburgh, USA. } \\
\text { Michael Mengel, } \\
\text { University of } \\
\text { Alberta, } \\
\text { Edmonton, } \\
\text { Canada }\end{array}$ \\
\hline Glomerular lesion BWG & $\begin{array}{l}\text { Assessment of } \\
\text { interobserver } \\
\text { reproducibility and } \\
\text { diagnostic significance of } \\
\text { established and alternative } \\
\text { glomerulitis and TG } \\
\text { scoring approaches }\end{array}$ & $\begin{array}{l}\text { A limited reproducibility of } \\
\text { glomerulitis and acceptable } \\
\text { reproducibility of TG scoring } \\
\text { was observed }\end{array}$ & $\begin{array}{l}\text { First trial and data analysis } \\
\text { completed. Follow-up trial } \\
\text { in preparation with the aim } \\
\text { to define reproducible } \\
\text { diagnostic thresholds for } \\
\text { glomerulitis and transplant } \\
\text { glomerulopathy }\end{array}$ & $\begin{array}{l}\text { Mark Haas, } \\
\text { Cedars Sinai } \\
\text { Hospital, Los } \\
\text { Angeles, USA } \\
\text { Banu Sis, } \\
\text { University of } \\
\text { Alberta, } \\
\text { Edmonton, } \\
\text { Canada }\end{array}$ \\
\hline Isolated v-lesion BWG & $\begin{array}{l}\text { Conduction of a } \\
\text { retrospective multicenter } \\
\text { study analyzing the } \\
\text { clinical significance of } \\
\text { isolated v-lesions }\end{array}$ & $\begin{array}{l}\text { Isolated v-lesion were found } \\
\text { to be associated with either } \\
\text { ABMR, or TCMR, or } \\
\text { delayed graft function, } \\
\text { indicating that a more } \\
\text { differentiated diagnostic and } \\
\text { tailored therapeutic approach } \\
\text { toward isolated v-lesion } \\
\text { cases is warranted }\end{array}$ & $\begin{array}{l}\text { Trial and data analysis } \\
\text { completed. Manuscript in } \\
\text { preparation }\end{array}$ & $\begin{array}{l}\text { Banu Sis, } \\
\text { University of } \\
\text { Alberta, } \\
\text { Edmonton, } \\
\text { Canada } \\
\text { Edward Kraus, } \\
\text { Johns Hopkins } \\
\text { University, } \\
\text { Baltimore, USA }\end{array}$ \\
\hline Implantation biopsies BWG & $\begin{array}{l}\text { Conduction of a } \\
\text { retrospective muticenter } \\
\text { study analyzing the } \\
\text { reproducibility (including } \\
\text { frozen versus paraffin) and } \\
\text { predictive value of lesions } \\
\text { in implantation biopsies }\end{array}$ & $\begin{array}{l}\text { The generated preliminary } \\
\text { trial data as well as those } \\
\text { available in the literature do } \\
\text { not justify discarding a } \\
\text { procured kidney solely based } \\
\text { on histological findings. The } \\
\text { sample size for the trial was } \\
\text { small and thus a follow-up } \\
\text { trial will be conducted }\end{array}$ & $\begin{array}{l}\text { First trial and data analysis } \\
\text { completed. Follow-up trial } \\
\text { in preparation }\end{array}$ & $\begin{array}{l}\text { Helen Liapis, } \\
\text { Gerge } \\
\text { Washington } \\
\text { University, St. } \\
\text { Louis, USA } \\
\text { Parmjeet } \\
\text { Randhawa, } \\
\text { University of } \\
\text { Pittsburgh, } \\
\text { Pittsburgh, USA }\end{array}$ \\
\hline Polyomavirus BWG & $\begin{array}{l}\text { Conduction of a } \\
\text { retrospective muticenter } \\
\text { study analyzing the } \\
\text { reproducibility and clinical } \\
\text { significance of a } \\
\text { provisional PVN scoring } \\
\text { schema proposed at the } \\
2009 \text { Banff meeting }\end{array}$ & $\begin{array}{l}\text { Acceptable reproducibility of } \\
\text { the in } 2009 \text { proposed grading } \\
\text { schema was seen. Group } \\
\text { discussion of the clinical } \\
\text { significance did not } \\
\text { generated consensus and thus } \\
\text { the proposal was not } \\
\text { integrated into the } \\
\text { classification at the } 2011 \\
\text { Banff meeting }\end{array}$ & $\begin{array}{l}\text { First trial completed. } \\
\text { Further data analysis } \\
\text { underway. Potential } \\
\text { follow-up trial under } \\
\text { consideration }\end{array}$ & $\begin{array}{l}\text { Volker Nickeleit, } \\
\text { University of } \\
\text { North Carolina, } \\
\text { Chapel Hill, USA }\end{array}$ \\
\hline Fibrosis BWG & $\begin{array}{l}\text { Assessment of } \\
\text { interobserver } \\
\text { reproducibility and clinical } \\
\text { significance of different } \\
\text { stains and methods for the }\end{array}$ & $\begin{array}{l}\text { A good correlation between } \\
\text { visual fibrosis assessment } \\
\text { using the trichrome stain } \\
\text { with computer and } \\
\text { immunohistochemistry- }\end{array}$ & $\begin{array}{l}\text { First trial and data analysis } \\
\text { completed. Follow-up trial } \\
\text { for testing refined criteria } \\
\text { for the assessment of }\end{array}$ & $\begin{array}{l}\text { Alton B Farris, } \\
\text { Emory } \\
\text { University, } \\
\text { Atlanta, USA }\end{array}$ \\
\hline
\end{tabular}




\begin{tabular}{|c|c|c|c|c|}
\hline $\begin{array}{l}\text { Banff Working Group } \\
\text { (BWG) }\end{array}$ & Scope & Preliminary results & Current activity status & $\begin{array}{l}\text { Lead and } \\
\text { contact person }\end{array}$ \\
\hline & $\begin{array}{l}\text { evaluation of interstitial } \\
\text { fibrosis in kidney biopsies } \\
\text { (allografts and native) }\end{array}$ & $\begin{array}{l}\text { based image analysis was } \\
\text { observed }\end{array}$ & $\begin{array}{l}\text { interstitial fibrosis is in } \\
\text { preparation }\end{array}$ & $\begin{array}{l}\text { Robert Colvin, } \\
\text { Massachusetts } \\
\text { General Hospital, } \\
\text { Boston, USA }\end{array}$ \\
\hline C4d-negative ABMR BWG & $\begin{array}{l}\text { Established at the } 2011 \\
\text { Banff meeting with the } \\
\text { aim to define diagnostic } \\
\text { criteria for C4d-negative } \\
\text { ABMR }\end{array}$ & None yet & $\begin{array}{l}\text { During an online } \\
\text { discussion after the } 2011 \\
\text { meeting available data } \\
\text { were reviewed and } \\
\text { currently efforts are } \\
\text { underway for designing } \\
\text { respective multicenter } \\
\text { studies with the aim to } \\
\text { define evidence-based } \\
\text { diagnostic criteria for C4d- } \\
\text { negative ABMR }\end{array}$ & $\begin{array}{l}\text { Mark Haas, } \\
\text { Cedars Sinai } \\
\text { Hospital, Los } \\
\text { Angeles, USA } \\
\text { Banu Sis, } \\
\text { University of } \\
\text { Alberta, } \\
\text { Edmonton, } \\
\text { Canada } \\
\text { Alexandre } \\
\text { Loupy, Hôpital } \\
\text { Européen } \\
\text { Georges } \\
\text { Pompidou, Paris, } \\
\text { France }\end{array}$ \\
\hline
\end{tabular}

